\title{
PRÁTICA REGULAR DO FUTEBOL: O ALTO RENDIMENTO DESTE ESPORTE ESTÁ ASSOCIADO A DANOS GENÉTICOS?
}

\author{
REGULAR PRATICE FOOTBALL: THE HIGH PERFORMACE OF THIS \\ SPORT IS RELATED TO GENETIC DAMAGE?
}

\author{
Marcelo Trotte Motta', Filipe Ferrari Ribeiro de Lacerda ${ }^{2}$, Alan Carlos Nery dos Santos ${ }^{3}$, Ana \\ Marice Teixeira Ladeia ${ }^{4}$, Jefferson Petto ${ }^{5}$
}

Autor para correspondência: Marcelo Trotte Motta - trottefisiol@yahoo.com.br Bacharel em Educação Física. Mestre em Biotecnologia. Professor da Universidade Estadual de Feira de Santana e da Faculdade Social da
Bahia, Salvador, Bahia, Brasil. ${ }^{2}$ Bacharel em Educação Física pela Faculdade Social da Bahia, Salvador, Bahia, Brasil. ${ }^{3}$ Fisioterapeuta. Mestre em Medicina e Saúde Humana. Professor na Universidade Salvador (UNIFACS), Salvador, Bahia, Brasil. ${ }^{4}$ Médica. Doutora em Medicina e Saúde. Professora na Escola Bahiana de Medicina e Saúde Pública, Salvador, Bahia, Brasil. ${ }^{5}$ Fisioterapeuta. Doutor em Medicina e Saúde Humana. Professor na Escola Bahiana de Medicina e Saúde Humana. Presidente da Comissão Científica do Departamento de Fisioterapia da Sociedade Brasileira de Cardiologia, Salvador, Bahia, Brasil.

RESUMO I Introdução: Estudos apontam que os exercícios físicos de intensidade moderada, especialmente os de endurance, têm efeito preventivo nas doenças cardiovasculares. Em contraposição, outros estudos mostram que o exercício quando praticado em alta intensidade induz à ocorrência de danos genéticos, os quais, por sua vez, associam-se ao processo de transformação maligna. Objetivo: Testar a hipótese de que atletas de futebol apresentam ocorrência de danos cromossômicos com maior aparecimento de micronúcleos, comparados com indivíduos sedentários ou praticantes de exercício físico não profissional. Métodos: A amostra analisada incluiu exclusivamente indivíduos do sexo masculino, de 18 a 38 anos, não fumantes, distribuídos em três grupos: Grupo l, formado por atletas de futebol, integrantes de um mesmo clube, submetidos à prática intensa de exercícios físicos; Grupo II, constituído por alunos da Universidade Estadual de Feira de Santana, matriculados no Programa de Exercício Físico do Laboratório de Atividade Física; e Grupo III, formado por indivíduos de hábitos sedentários. Resultados: Um total de 52.000 células foram analisadas. A análise das diferenças entre as médias de micronúcleos calculadas, feita com o uso da análise de variância, com um critério de classificação, não revelou diferença significante entre os grupo estudados $(F 2,49=0,11 ; p=0,88)$. Conclusão: Em conclusão, nosso estudo mostrou que a prática do futebol por atletas profissionais de alta intensidade não acarreta em danos ao DNA.

\begin{abstract}
Introduction: Studies indicate that moderate intensity physical exercises, especially those of endurance, have a preventive effect on cardiovascular diseases. However, other studies show that exercise when practiced at high intensity induces the occurrence of genetic damage, which, in turn, are associated with the malignant transformation process. Objective: To test the hypothesis that football athletes present occurrence of chromosomal damage with greater appearance of micronuclei compared to sedentary individuals or nonprofessional practitioners of physical exercise. Methods: The sample included only males, 18-38 years old, nonsmokers, divided into three groups: Group I, formed by football athletes, members of the same club, subjected to intense physical exercise; Group II, consisting of students from the State University of Feira de Santana, enrolled in the Exercise Program Physical Activity Laboratory; and Group III, formed by individuals of sedentary habits. Results: A total of 52,000 cells were analyzed. The analysis of the differences between the averages calculated micronuclei done using analysis of variance with a classification criterion, showed no significant difference between the group studied (F2,49 $=0.11, p$ $=0.88$ ). Conclusion: In conclusion, our study showed that the practice of football by high-intensity professional athletes does not cause damage to DNA.
\end{abstract}

Descriptors: Football; DNA Damage; Free Radicals; Physical and Rehabilitation Medicine

Descritores: Futebol; Dano ao DNA; Radicais Livres; Medicina Física e Reabilitação. 


\section{INTRODUÇÃO}

Segundo alguns autores', os treinamentos físicos moderados, particularmente os exercícios de endurance, têm efeito preventivo não apenas nas doenças cardiovasculares, mas, também sobre o câncer, além de desempenharem importante papel na reabilitação dos indivíduos acometidos por estas doenças. Em outros estudos, entretanto, foi mostrado que a prática de exercício físico, principalmente quando feito em alta intensidade, induz à ocorrência de danos genéticos os quais, por sua vez, associamse ao processo de transformação maligna ${ }^{2}$.

Westerlind ${ }^{3}$ chama a atenção para a necessidade crescente de realização de estudos que avaliem o potencial do exercício físico em inibir ou favorecer o desenvolvimento do câncer. $O$ que este autor questiona é: "Quais seriam as sobrecargas (volume e intensidade do exercício) efetivas em exercer um efeito protetor e em que níveis a prática do exercício físico propiciaria o desenvolvimento do câncer?". Esses questionamentos têm fundamento no fato de que $\circ$ exercício promove estresse oxidativo com consequente aumento dos radicais livres, quando acima de volume ou intensidade adequados ${ }^{4}$.

Segundo Kehrer \& $\mathrm{Klotz}^{5}$, os radicais livres são essenciais para muitos processos biológicos normais, todavia, podem levar a efeitos indesejáveis se sua produção não for controlada. O número elevado de espécies reativas de oxigênio que são geradas pode potencialmente resultar em danos para lipídios, proteínas e DNA ${ }^{6}$.

Uma vez que a relação entre danos genéticos e câncer está bem estabelecida, o biomonitoramento de populações sob risco de maior ocorrência destes danos é um passo importante na prevenção dessa doença ${ }^{7}$. Entre os testes citogenéticos que têm sido utilizados para o biomonitoramento de populações humanas, destaca-se o Teste de Micronúcleo, realizado em linfócitos ou em células epiteliais esfoliadas ${ }^{8}$.

Micronúcleos são estruturas delimitadas por membrana, de constituição similar à do núcleo e dele distintamente separadas. Eles são formados por exclusão de cromossomos inteiros ou de fragmentos cromossômicos que, durante a divisão celular, falham em sua ligação ao fuso e, assim não são incluídos no núcleo das células filhas, permanecendo no citoplasma das células interfásicas.

A ocorrência de micronúcleos em linfócitos circulantes, relacionada à prática de exercício físico foi avaliada por Schiffl; Zieres e Zankl ${ }^{9}$. Esses autores mostraram que o exercício físico exaustivo aumenta a freqüência de micronúcleos, evidenciando, assim, os efeitos genotóxicos do estresse oxidativo induzido pelo excesso da atividade física. Esses resultados corroboram com os obtidos por Pereira e cols. ${ }^{10}$, que evidenciaram a ocorrência de danos ao DNA em consequência do exercício físico utilizando o Teste Cometa.

A prática intensa de exercícios físicos é desempenhada por atletas de diversas modalidades esportivas, destacando-se entre elas o futebol. Em atletas de elite do futebol, a duração do exercício em alta intensidade no decorrer dos 90 minutos de uma partida é estimada em sete minutos, o que corresponde a $8 \%$ do tempo total de jogo, incluindo cerca de 19 corridas intensas com duração média, cada uma, de dois segundos ${ }^{11}$. Apesar da dificuldade em mensurar a contribuição das vias aeróbias durante uma partida de futebol, é estimado que a contribuição desta via seja em média de três litros de oxigênio consumidos por minuto ${ }^{12}$. Tendo em vista a prática intensa de exercício físico necessária ao desempenho dos atletas de futebol - e levando em conta o potencial do estresse oxidativo em lesar o DNA - aventa-se a hipótese de haver possibilidade de ocorrência de danos cromossômicos em atletas do futebol, devido à produção de radicais livres gerados nessa atividade.

Portanto, o objetivo deste estudo foi testar a hipótese de que atletas de futebol apresentam ocorrência de danos cromossômicos com maior aparecimento de micronúcleos, comparados com indivíduos sedentários ou praticantes de exercício físico não profissional. 
A pesquisa foi realizada em consonância com a Resolução 466/1 2 do Conselho Nacional de Saúde. Foi aprovada pelo Comitê de Ética da Universidade Estadual de Feira de Santana (Protocolo 058/2006 e CAAE 0054.0.059.000-06). A participação foi voluntária, e todos - após leitura do Termo de Consentimento Livre e Esclarecido - procederam à sua assinatura.

A amostra analisada incluiu exclusivamente indivíduos do sexo masculino, de 18 a 38 anos, não fumantes, distribuídos em três grupos: Grupo I, formado por atletas de futebol, integrantes de um mesmo clube, submetidos à prática intensa de exercícios físicos; Grupo II, constituído por alunos da Universidade Estadual de Feira de Santana, matriculados no Programa de Exercício Físico do Laboratório de Atividade Física; e Grupo III, formado por indivíduos de hábitos sedentários. Foi coletado material de sessenta indivíduos, oito dos quais foram excluídos da amostra porque o número de células não foi suficiente para análise. Portanto, a amostra foi constituída por 52 indivíduos: 15 do Grupo I, 18 do Grupo II e 19 do Grupo III.

A caracterização da amostra foi feita através de questionário contendo indagações a respeito da idade, hábito de ingerir bebidas alcoólicas, exposição a outros genotóxicos e prática de atividade física.

Foram considerados bebedores os indivíduos que referiram uso de bebidas alcoólicas de qualquer tipo há mais de seis meses, com frequência de pelo menos duas vezes por semana.

Nenhum indivíduo do Grupo l informou uso de bebida alcoólica em frequência maior do que uma vez por semana. Dois deles informaram uso quinzenal e cinco bebiam esporadicamente. Seis pessoas do Grupo II faziam uso de bebidas alcoólicas duas vezes por semana e oito o faziam esporadicamente. No Grupo III, apenas duas pessoas foram classificados como bebedores, informando uso de bebidas duas vezes por semana. Neste Grupo, oito indivíduos bebiam uma vez por semana e três esporadicamente.

COLETA DO MATERIAL E CULTURA DE LINFÓCITOS
O preparo do material foi feito em consonância com o método proposto por Fenech 13, com algumas modificações. O sangue foi coletado pela manhã - nos grupos I e II, antes das atividades físicas sem a necessidade de jejum. Os integrantes do grupo I realizaram suas respectivas atividades futebolísticas de alta intensidade no dia anterior à coleta, no turno vespertino. De cada indivíduo que integrou a amostra, foram coletados $10 \mathrm{ml}$ de sangue periférico por punção venosa, utilizando seringa descartável e estéril. $O$ sangue assim coletado foi imediatamente vertido em tubo falcon contendo EDTA ( 1 gota para cada $5 \mathrm{ml}$ de sangue) e em seguida o material foi vertido em outro tubo falcon de $15 \mathrm{ml}$, contendo $3 \mathrm{ml}$ de histopaque (Sigma), o que foi feito evitando homogeneização. Os linfócitos mononucleados foram devidamente fracionados em gradiente de densidade Histopaque (centrifugação feita em velocidade de $1500 \mathrm{rpm}$ durante 40 minutos). Após a centrifugação, os linfócitos foram pipetados e adicionados (106 células $/ \mathrm{ml}$ ) a tubo falcon contendo $5 \mathrm{ml}$ de meio de cultura RPMI 1640 (Gibco). Em seguida, foi feita nova centrifugação em velocidade de $1500 \mathrm{rpm}$ durante 10 minutos, após o que o sobrenadante foi descartado e ao pellet adicionado $1 \mathrm{ml}$ de RPMI 1640. O pellet foi ressuspenso e transferido $(200 \mu \mathrm{L})$ para placa de cultura, cada uma delas com cinco poços contendo um mix de $1 \mathrm{ml}$ constituído por $10 \%(\mathrm{v} / \mathrm{v})$ de soro bovino fetal (Gibco), 1\% de L-glutamina (Gibco), 1\% de antibióticos (penicilina, 100U/mL, estreptomicina, $100 \mu \mathrm{g} / \mathrm{mL}$ e anfotericina $B, 25 \mu \mathrm{g} /$ $\mathrm{mL}$; Gibco) e $2 \%(\mathrm{v} / \mathrm{v})$ de fitohemaglutinina $A$ (Gibco), complementado com RPMI 1640 (Gibco). Após esses procedimentos, a cultura foi mantida a $37^{\circ} \mathrm{C}$ em estufa de CO2 (5\%) (BIOSYSTEMS). Após 44 horas, $6 \mu \mathrm{g} / \mathrm{mL}$ de citocalasina B (Sigma) foram adicionadas à cultura. Ao fim do período de cultivo (72 horas), as células foram novamente pipetadas dos cinco poços e colocadas em um tubo falcon, devidamente identificado, para centrifugação a 800 rpm por 10 minutos e à temperatura ambiente. Após esta centrifugação o sobrenadante foi novamente descartado, sendo mantido $1 \mathrm{ml}$ do meio para que as células fossem ressuspensas. Logo em seguida foram cuidadosamente adicionadas em $4 \mathrm{ml}$ da solução fixadora (metanol a $70 \%$ e ácido acético na proporção de 3:1), e o tubo foi levado 
para geladeira onde permaneceu durante 20 minutos. Findo este tempo, foram realizadas duas centrifugações em velocidade de $800 \mathrm{rpm}$ durante 10 minutos. Após cada uma delas o sobrenadante foi descartado e ao pellet adicionado $5 \mathrm{ml}$ de solução fixadora, sendo o pellet mais uma vez ressuspenso. Após o último descarte do sobrenadante, foram adicionados 700 microlitros de solução fixadora, e o pellet novamente ressuspenso, após o que a suspensão foi gotejada em quatro lâminas (com identificação codificada e correspondente à do tubo) deixadas para secar ao ar e então coradas por 15 minutos com a solução de Giemsa (4\%; Gibco) em tampão fosfato salino de Dulbecco $(\mathrm{pH}$ 7,1; Gibco).

\section{ANÁLISE CITOGENÉTICA}

A análise citogenética foi realizada em teste cego, sob microscopia óptica, com aumento de 1000X. A observação da ocorrência de micronúcleos foi feita, para cada indivíduo, em 1000 células binucleadas (Figura 1). Foram computadas apenas as células binucleadas em que os núcleos apresentassem tamanho e coloração similar, com limites nucleares e citoplasmáticos bem definidos. Os critérios adotados para identificação de micronúcleos foram aqueles descritos por Fenech et $\mathrm{al}^{14}$. Foram considerados micronúcleos as estruturas arredondadas ou ovaladas, distintamente separadas dos núcleos, vistas no mesmo plano que estes, medindo de um sexto até um terço do tamanho deles e com coloração e distribuição cromatínica similar (Figura 2).

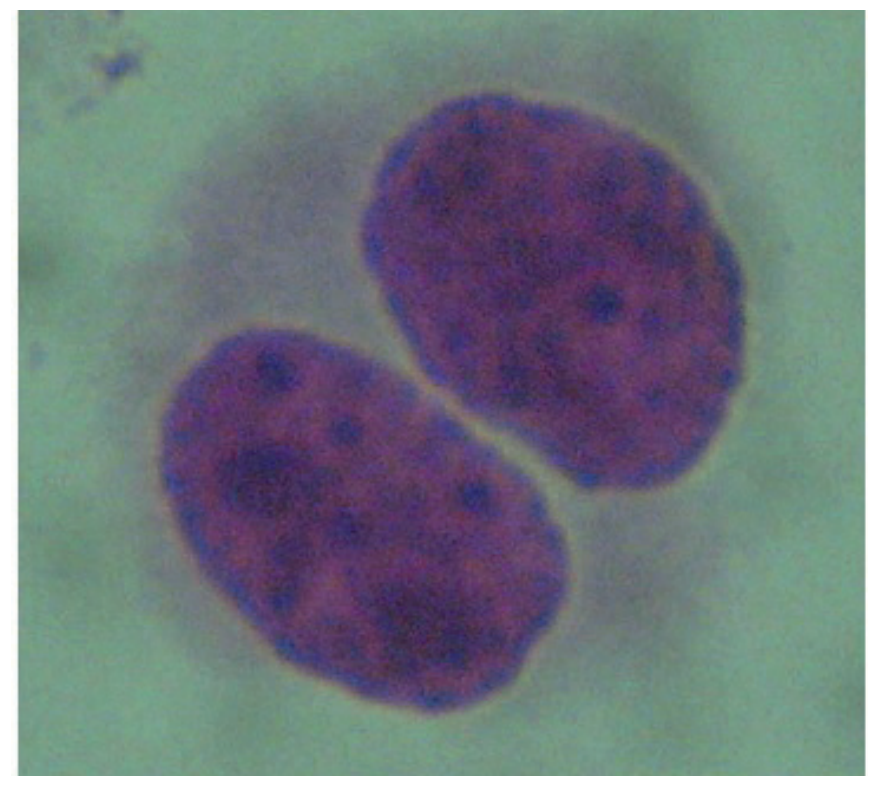

Figura 1. Linfócito binucleado (1000 X)

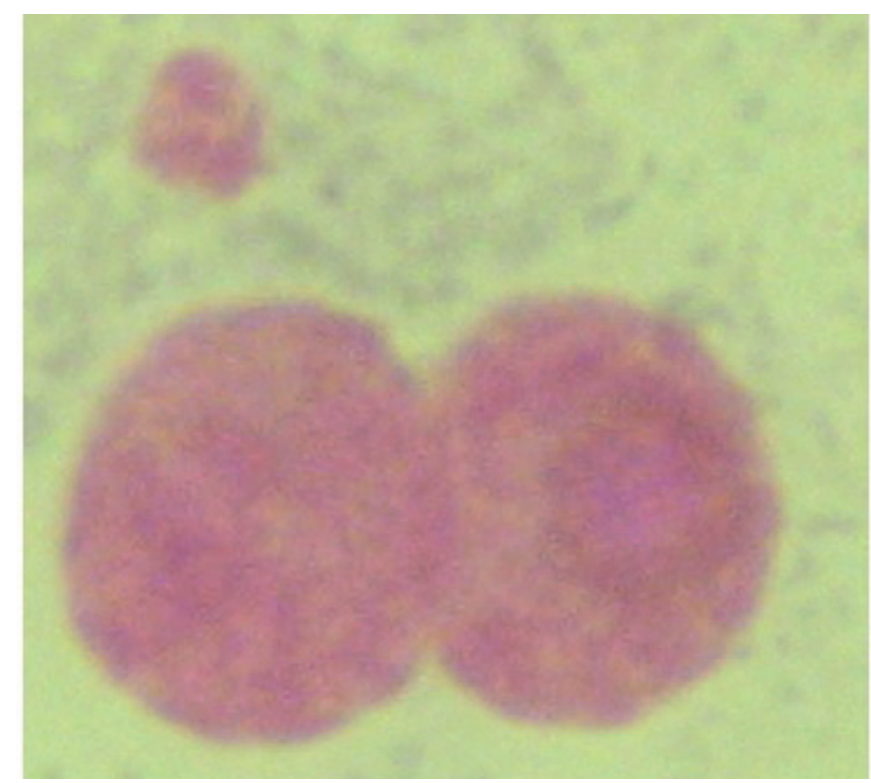

Figura 2. Micronúcleo em Linfócito binucleado (1000 X)

\section{ANÁLISE ESTATÍSTICA}

A avaliação das diferenças entre os grupos relativa à idade foi feita com o uso da Análise de Variância com um critério de classificação. Para análise das tabelas de associação, levando em conta parâmetros considerados no questionário (hábito de beber) foi utilizado o teste de Qui-quadrado (X2). A análise relativa à ocorrência de micronúcleos foi feita de dois modos: 1) Empregando a análise de variância, desde que possível a pressuposição de normalidade; 2) uso do teste condicional para comparação de proporções em situações de eventos raros. Este é um teste de significância alternativo ao de qui-quadrado, na linha do teste exato de Fisher e adequado à avaliação de eventos citogenéticos, quando uma grande amostra de células é necessária para detecção da ocorrência de uma determinada aberração cromossômica. Em todas as análises o nível de significância adotado foi de $5 \%$.

\section{RESULTADOS}

\section{CARACTERÍSTICAS DA AMOSTRA}

Idade

A média calculada de idade (anos) da amostra total (XiD) foi $22 \pm 4,0$ e as obtidas para os Grupos I, II 
e III foram respectivamente $21 \pm 4,4 ; 22 \pm 3,1$ e $23 \pm 4,4$. A análise das diferenças entre as médias observadas nos três grupos, feita com o uso da análise de variância, com um critério de classificação, não revelou diferença significante $(F 2,49=1,0, p=0,35)$.

Prática de Exercício Físico

Todos os indivíduos do Grupo I eram submetidos a treinamento de futebol profissional diariamente. Os indivíduos do grupo Il informaram em sua maioria prática variada de exercícios. Os níveis de cansaço e fadiga durante as atividades físicas foram mensurados segundo a Escala de Borg. Indivíduos dos Grupos I e II são apresentados na Tabela 1.

Tabela 1. Dados relativos à prática de atividade física dos grupos ativos.

\begin{tabular}{|c|c|c|}
\hline Atividade Física & Grupo I (N) & Grupo II (N) \\
\hline \multicolumn{3}{|l|}{ Tipo } \\
\hline Futebol & 15 & 2 \\
\hline Musculação & & 5 \\
\hline Natação & & 1 \\
\hline Mais de um tipo & & 5 \\
\hline Outros & & 5 \\
\hline \multicolumn{3}{|l|}{ Tempo (meses) } \\
\hline 01 a 04 & & 1 \\
\hline 05 a 08 & & 2 \\
\hline 09 a 12 & & 3 \\
\hline 13 a 24 & & 0 \\
\hline$>24$ & 15 & 12 \\
\hline \multicolumn{3}{|c|}{ Frequência Semanal } \\
\hline 01 a 02 & & 1 \\
\hline 03 a 04 & & 11 \\
\hline 05 a 06 & & 06 \\
\hline$>06$ & 15 & \\
\hline \multicolumn{3}{|c|}{ Duração (minutos) } \\
\hline$<30$ & & 0 \\
\hline$=30$ & & 0 \\
\hline$>30$ & & 1 \\
\hline$=60$ & & 7 \\
\hline$>60$ & 15 & 10 \\
\hline \multicolumn{3}{|l|}{$\begin{array}{l}\text { Intensidade } \\
\text { Leve }\end{array}$} \\
\hline Moderada & & 07 \\
\hline Alta & 13 & 11 \\
\hline Extenuante & 02 & \\
\hline
\end{tabular}


Um total de 52.000 células foram analisadas. A análise das diferenças entre as médias de micronúcleos calculadas, feita com o uso da análise de variância, com um critério de classificação, não revelou diferença significante $(F 2,49=0,11 ; p=0,88)$. Dados apresentados na Tabela 2.

Tabela 2. Médias de micronúcleos observadas nos grupos avaliados

\begin{tabular}{lcccc}
\hline Grupos & TCA & TMNI & $\mathrm{X}_{\text {MN }} \pm$ D.P & $\mathrm{F}_{2,49}$ \\
\hline I & 15.000 & 30 & $2,0 \pm 1,8$ & \\
II & 18.000 & 35 & $1,9 \pm 1,6$ & 0,11 \\
III & 19.000 & 33 & $1,7 \pm 1,5$ & $\mathrm{p}=0,88$ \\
I+II+III & 52.000 & 98 & $1,8 \pm 1,6$ & \\
\hline
\end{tabular}

*TCA: Total de células analisadas; TMNI: Total de micronúcleos.

As diferenças observadas nas frequências de micronúcleos foram também avaliadas com $\circ$ uso do teste condicional para comparação de proporções em situações de eventos raros. Os resultados obtidos também não revelam significância estatística (Tabela 3).

Tabela 3. Frequências de micronúcleos.

\begin{tabular}{ccccc}
\hline Grupo & TCA & TMNI & MNR & X $^{2}$ \\
\hline I & 15.000 & 30 & 28,2 & 0,3603 \\
II & 18.000 & 35 & 33,9 & G.L.=2 \\
III & 19.000 & 33 & 35,8 & p = 0,72 \\
\hline
\end{tabular}

*TCA: Total de células analisadas; TMNI: Total de micronúcleos; MNR: Frequência de micronúcleos.

\section{Ocorrência de Micronúcleos em Função da Idade}

A análise da distribuição de micronúcleos em relação à idade dos indivíduos na amostra total e nos Grupos l, II e III, isoladamente, feita pelo teste condicional de proporção para eventos raros, com os valores de idade distribuídos em duas categorias pelo valor da mediana $(M=21)$, não mostrou diferença significante. Dados apresentados na Tabela 4.

Tabela 4. Análise da distribuição de micronúcleos em relação à idade

\begin{tabular}{|c|c|c|c|c|c|c|c|c|c|}
\hline Grupo & $\begin{array}{l}\mathrm{N} \\
(\leq 21)\end{array}$ & $\begin{array}{l}N \\
(\geq 21)\end{array}$ & $\begin{array}{l}\# \text { de } \\
\text { cél } \\
\leq 21\end{array}$ & $\begin{array}{l}\# \text { de } \\
\text { cél } \\
\geq 21\end{array}$ & $\begin{array}{l}\text { MN } \\
\text { (obs) } \\
\leq 21\end{array}$ & $\begin{array}{l}M N(\text { esp) } \\
\leq 21\end{array}$ & $\begin{array}{l}\text { MN } \\
\text { (obs) } \\
\geq 21\end{array}$ & $\begin{array}{l}M N \text { (esp) } \\
\geq 21\end{array}$ & $\mathrm{X}^{2} ;$ G.L. $=1$ \\
\hline $\mathrm{I}$ & 11 & 04 & 11000 & 4000 & 24 & 22,0000 & 06 & 08,0000 & $\begin{array}{l}0,68 \\
p>0,30\end{array}$ \\
\hline II & 08 & 10 & 8000 & 10000 & 15 & 15,5556 & 20 & 19,4444 & $\begin{array}{l}0,03 \\
p>0,70\end{array}$ \\
\hline III & 09 & 10 & 9000 & 10000 & 12 & 15,6316 & 21 & 17,3684 & $\begin{array}{l}1,60 \\
p>0,10\end{array}$ \\
\hline$|+||+|||$ & 28 & 24 & 28000 & 24000 & 51 & 52,7692 & 47 & 45,2308 & $\begin{array}{l}0,12 \\
p>0,70\end{array}$ \\
\hline
\end{tabular}




\section{DISCUSSÃO}

De acordo ao nosso conhecimento, 0 presente estudo foi realizado para avaliar - pela primeira vez - a influência do futebol de alta intensidade na estabilidade do DNA. Portanto, esta pesquisa representa uma contribuição para a real avaliação dos efeitos que podem resultar da prática excessiva, ou não, do exercício físico, especialmente o futebol de alta intensidade. Os resultados aqui apresentados, baseados nas condições experimentais em que foi realizado, não demonstram indução de danos cromossômicos expressados como micronúcleos pelo exercício físico em atletas de futebol.

O registro na literatura da ocorrência de micronúcleos em função da atividade física é escasso e teve início com o estudo de Schiff; Zieres e Zankl ${ }^{9}$ em 1997. Nesse estudo, os autores avaliaram a ocorrência de micronúcleos em apenas seis indivíduos, computando - aparecimento dessas estruturas em 3000 linfócitos binucleados, cultivados $24 \mathrm{~h}$ e $48 \mathrm{~h}$ após duas sequências de exercícios intensos. $O$ número médio de micronúcleos aumentou significativamente nos dois períodos, tendo os autores concluído que - exercício físico causa severas mutações ao nível cromossômico nos linfócitos sanguíneos.

Contrapondo 0 que Schiffl; Zieres e Zankl ${ }^{9}$ apresentaram, Hartmann e outros 15 analisaram as frequências de micronúcleos em 1000 linfócitos binucleados coletados de seis indivíduos (três homens e três mulheres), que em um período de um a sete anos estiveram engajados em treinamento para competição de triathlon. A análise de micronúcleos foi feita $24 \mathrm{~h}$ e $96 \mathrm{~h}$ após os atletas terem nadado $1,5 \mathrm{~km}$, pedalado $40 \mathrm{~km}$ e corrido $10 \mathrm{~km}$. A comparação entre as frequências de micronúcleos observadas nesses períodos e aquela observada antes das atividades não mostrou diferença significativa.

Resguardadas as diferenças entre o presente estudo e os de Hartmann e colaboradores ${ }^{15}$ e Umegaki e outros $^{16}$, particularmente no que tange ao tipo de atividade física praticada, os resultados aqui obtidos corroboram com aqueles descritos por esses autores, sugerindo que os efeitos de espécies de radicais livres liberados em consequência da atividade física intensa não demonstram danos genéticos traduzidos como micronúcleos. Importante salientar que, no estudo de Umegaki e outros ${ }^{16}$, o grupo de indivíduos não treinados apresentou importantes alterações em lesões cromossômicas induzidas por raios- $X$, levando a crer que o contraste destas lesões entre indivíduos treinados e não treinados pode estar relacionado com um melhor sistema de reparação do DNA, bem como melhor atividade de enzimas antioxidantes endógenas.

Além disso, nossos achados também se assemelham ao estudo de Hartmann e outros ${ }^{15}$ no quesito frequência de micronúcleos, que tendeu a ser menor em atletas de alta intensidade, embora a diferença entre os grupos não tenha sido significativa, o que corrobora também com a presente pesquisa. Isto sugere que o organismo de atletas mais bem treinados gera adaptações que promovem melhorias na defesa contra radicais livres, bem como melhor reparo a danos em DNA após a prática do exercício ${ }^{17}$. Isso pode ser atribuído a um melhor estímulo e posterior capacidade dos sistemas antioxidantes endógenos em indivíduos mais treinados, consequentemente com melhor equilíbrio oxidativo durante o exercício ${ }^{17}$, bem como maior efetividade na corrente de elétrons mitocondrial ${ }^{18}$.

Apesar da associação entre os resultados aqui obtidos e os dos autores supracitados, deve-se ressaltar que a nossa coleta de sangue foi realizada quase 24 horas após a realização da atividade física. Entretanto, os atletas que compunham o grupo I tinham mais de 10 anos de prática no esporte, com volume acima de 6 sessões semanais de 60 minutos, em intensidade alta e extenuante. Os indivíduos do grupo II praticavam atividades físicas diversas há mais de 6 meses, com volume maior ou igual a 3 vezes semanais e intensidade variando entre moderada, alta e extenuante.

Alguns achados evidenciam, inclusive, redução na frequência de micronúcleos advindos de exercícios intensos. Reichhold e outros ${ }^{19}$ investigaram os efeitos de uma prova de Ironman e observaram diminuição altamente significativa no número de células binucleadas com micronúcleos de 5 a 19 dias após a prova. No subgrupo muito treinado, esta redução foi notada também no período de 2 
dias antes do triathlon até $20 \mathrm{~min}$ após. Ratificando estes resultados, Pittaluga e outros ${ }^{20}$ demonstraram maiores danos cromossômicos no grupo menos treinado.

Em suma, os autores enfatizam a hipótese de que o treinamento regular pode promover mecanismos adaptativos, incluindo mecanismos de reparação, e potencialização da atividade antioxidante endógena, que pode prevenir o estresse oxidativo e consequente dano ao DNA, mesmo após o exercício extenuante $^{19}$. No entanto, em nosso estudo esse efeito benéfico do exercício não foi evidenciado. Uma possível justificativa para tal resultado, seja a diferença entre os protocolos, pois o volume e intensidade de exercício do estudo de Reichhold e outros $^{19}$ é muito mais extenuante do que o futebol.

É interessante chamar à atenção que tipos divergentes de testes podem mostrar diferentes tipos de alterações do DNA. Por exemplo, o ensaio CBMN é capaz de detectar mutações persistentes de um ciclo mitótico, pelo menos; já lesões em DNA passíveis de reparo - como sítios alcalino-lábeis são detectados pelo ensaio $\mathrm{SCGE}^{21}$, o qual dosa dano em DNA por fluorescência.

Fazendo uso do Teste Cometa, outros autores 10 também descreveram aumento nos danos ao DNA, em consequência do exercício físico. Comparandose homens treinados em corrida e não-treinados, foi detectado aumento na migração do DNA, em todos os indivíduos, $24 \mathrm{~h}$ após o término de uma corrida até a exaustão. Porém, comparativamente, níveis significativamente maiores foram observados naqueles não-treinados, o que, segundo os autores, sugere que a adaptação ao treinamento é capaz de reduzir os efeitos dos radicais livres sobre o DNA.

Apesar de tais resultados, sugere-se que o exercício prolongado ou extenuante pode levar à produção de ROS, fortalecendo a suscetibilidade para danos musculares, além de danos no DNA22. Assim sendo, Pittaluga e cols. ${ }^{20}$ avaliaram 18 indivíduos jovens e saudáveis num teste exaustivo no cicloergômetro - sendo 6 deles ciclistas profissionais (VO2máx $66,2 \mathrm{ml} / \mathrm{min} / \mathrm{kg}, 13 \mathrm{~h}$ de treinamento por semana) e os demais subdivididos em um grupo de VO2máx baixo e baixa frequência de atividade física $(47,1 \mathrm{ml} / \mathrm{min} / \mathrm{kg}$ e $3,6 \mathrm{~h} /$ semana $)$ e outro com esses parâmetros a níveis intermediários $(56,7 \mathrm{ml} / \mathrm{min} /$ $\mathrm{kg}$ e $8 \mathrm{~h} /$ semana). Na avaliação de ocorrência de micronúcleos, bloquearam a citocinese com citocalasina $B$, respeitando o protocolo $C B M N$.

Os atletas profissionais apresentaram maior razão GSSG/GSH, sugerindo estresse oxidativo e frequência de micronúcleos. No entanto, não mostraram agravamento após o teste físico. Por outro lado, o grupo com menor frequência de treinamento demonstrou tendência de aumento, tanto $30 \mathrm{~min}$ quanto $24 \mathrm{~h}$ após o teste; os sujeitos de frequência intermediária apresentaram valores inalterados ao longo do tempo. A frequência de apoptose espontânea nos linfócitos periféricos aumentou $30 \mathrm{~min}$ após o exercício nos três grupos - sendo estatisticamente significativa apenas nos atletas - mas voltou aos níveis basais em $24 \mathrm{~h}$. Em outras palavras, supõe-se que o treinamento físico muito intenso pode estar associado com agressão oxidativa crônica, enquanto estresse leve oriundo de treinamento moderado induz estimulação e manutenção nos sistemas de reparo.

Mais recentemente, Franzke e outros ${ }^{23}$ apresentaram a importância do condicionamento físico aeróbio em idosos sedentários, o que parece gerar menor dano cromossômico, utilizando o teste de 6 min. Além de melhor condicionamento aeróbio culminar em menor dano genético, a idade e frequência de $\mathrm{MN}$ foram significativamente correlacionadas, como relatado recentemente por outros autores ${ }^{24}$. Houve um aumento significativo até os 60 anos, porém, acima disso, esta frequência tendeu à estabilidade, traduzindo-se em maior resistência contra formação de MN.

Um ano mais tarde, avaliando o mesmo grupo de idosos, Franzke e colaboradores ${ }^{25}$ investigaram - efeito do treinamento de resistência (TR), treinamento de resistência com uso de suplementos (TRS) e intervenção cognitiva (C) em quebras no DNA de células mononucleares do sangue periférico. No grupo TR houve um aumento de $22 \%$ na atividade de catalase e no TRS, um aumento de $6 \%$ na superóxido dismutase. Os homens tenderam a apresentar maiores taxas de danos de DNA do que as mulheres, o que pode ter sido causado pelo aumento do nível de estrogênio nas mulheres, refletindo num melhor sistema de defesa antioxidante. $O$ grupo TR teve aumento nas taxas de danos no DNA, medidos com - Teste Cometa. No entanto, se mostraram dentro dos níveis de normalidade. Outro fato interessante 
é que, após 6 meses de TR ou TRS, aumentou a atividade antioxidante, confirmando a importância da atividade física. Surpreendentemente, o grupo C apresentou resultados semelhantes aos de intervenção física nos parâmetros do Teste Cometa e na atividade de enzimas antioxidantes. Em suma, este estudo fortalece a importância da aptidão aeróbica com menor risco de taxa para dano cromossômico.

O presente estudo apresenta algumas limitações, a exemplo da coleta do sangue periférico ter sido feita apenas em um dia aleatório, antes dos exercícios - não podendo ser avaliada a ocorrência de micronúcleos logo após, ou horas após as atividades, como procederam outros autores. Assim, não podemos generalizar os resultados aqui obtidos, sendo necessário estudos adicionais que investiguem a ocorência de micronúcleos em jogadores profissionais de futebol. Acresce, ainda, que este trabalho não distinguiu os jogadores pela sua posição específica, como goleiros ou atacantes. Porém, a coleta e o processo foram realizados de forma atenta e minuciosa.

Em conclusão, nosso estudo mostrou que a prática do futebol por atletas profissionais de alta intensidade não acarreta em danos ao DNA, analisados através do ensaio CBMN. Este fato pode ser atribuído a mecanismos adaptativos no sistema de reparação e de enzimas antioxidantes endógenas, fortalecendo a prevenção dos efeitos do estresse oxidativo mesmo após exercício físico intenso.

\section{CONCLUSÃO}

Da análise da literatura e considerando os resultados obtidos neste estudo, é possível supor que a indução de danos genéticos em consequência da prática intensiva do exercício físico esteja na dependência da quebra do equilíbrio fisiológico entre $\circ$ metabolismo aeróbico/anaeróbico. Tais danos podem ser traduzidos em diferentes endpoints citológicos, os quais ainda não estão suficientemente consubstanciados com dados da literatura, para que possam ser, no presente momento, utilizados como biomarcadores de risco. Sendo assim, os efeitos clastogênicos e aneugênicos consequentes à ação de radicais livres, liberados em consequência do exercício físico, tal como avaliados neste estudo, não puderam ser observados em linfócitos. Dessa forma, estudos adicionais se fazem necessários para a real avaliação do uso de micronúcleos como biomarcadores de risco em função da prática exacerbada do exercício físico.

\section{CONTRIBUIÇÕES DOS AUTORES}

Concepção e desenho da pesquisa: Motta MT, Petto J; Obtenção de dados: Trotte MM, Lacerda FFR; Análise e interpretação de dados: Motta MT, Santos ACN, Ladeia AMT, Petto J; Redação do manuscrito: Motta MT, Santos ACN, Lacerda FFR, Petto J; Revisão crítica do manuscrito quanto ao conteúdo intelectual: Motta MT, Lacerda FFR, Santos ACN, Ladeia AMT, Petto J.

\section{CONFLITO DE INTERESSES}

Nenhum conflito financeiro, legal ou político envolvendo terceiros (governo, empresas e fundações privadas, etc.) foi declarado para nenhum aspecto do trabalho submetido (incluindo mas não limitandose a subvenções e financiamentos, conselho consultivo, desenho de estudo, preparação de manuscrito, análise estatística.

\section{REFERÊNCIAS}

1. Wolff G, Toborek M. Targeting the Therapeutic Effects of Exercise on Redox-Sensitive Mechanism in the Vascular Endothelium During Tumor Progression. IUBMB Life. 2013;65(7):565-571. doi: 10.1002/iub. 1169

2. Cuevas MJ, Almar M, García-Glez JC, García-López D, De Paz JÁ, Alvear-Ordenes I et al. Changes in oxidative stress markers and NF-kappaB activation induced by sprint exercise. Free Radic Res. 2005;39(4):431-9

3. Westerlind KC. Physical activity and cancer preventionmechanisms. Med Sci Sports Exerc. 2003;35(1 1):1 834-1840. doi: 10.1249/01.MSS.0000093619.37805.B7

4. Yavari A, Javadi M, Mirmiran P, Bahadoran Z. ExerciseInduced Oxidative Stress and Dietary Antioxidants. Asian J Sports Med. 201 5;6(1):1-7. doi: 10.5812/asjsm.24898

5. Kehrer JP, Klotz LO. Free radicals and related reactive species as mediators of tissue injury and disease: implications for Health. Crit Rev Toxicol. 2015;45(9):765-798. doi: $10.3109 / 10408444.2015 .1074159$

6. Mello T, Zanieri F, Ceni E, Galli A. Oxidative Stress in the 
Healthy and Wounded Hepatocyte: A Cellular Organelles Perspective. Oxid Med Cell Longev. 2016;2016:1-15. doi: $10.1155 / 2016 / 8327410$

7. Singaraju $M$, Singaraju S, Parwani $R$, Wanjari S.

Cytogenetic biomonitoring in petrol station attendants: $A$ micronucleus study. J Cytol. 2012;29(1):1-5

8. de Carvalho CAP. Frequência de micronúcleos em células esfoliadas da mucosa bucal de pacientes obesos [Doutorado em Odontologia]. Bauru: Faculdade de Odontologia de Bauru, Universidade de São Paulo; 2012

9. Schiff C, Zieres C, Zankl H. Exhaustive physical exercise increases frequency of micronuclei. Mutat Res. 1997;389123):243-246

10. Pereira BC, Pauli JR, Antunes LM, de Freitas EC, de Almeida MR, de Paula Venâncio $V$ et al. Overtraining is associated with DNA damage in blood and skeletal muscle cells of Swiss mice. BMC Physiol. 2013;13(1 1):1 -9. doi: 10.1186/1472-6793-13-11

11. Bangsbo J. The physiology of soccer--with special reference to intense intermittent exercise. Acta Physiol Scand Suppl. 1994;619:1-155

12. Impellizzeri FM, Rampinini E, Marcora SM. Physiological assessment of aerobic training in soccer. J Sports Sci. 2005;23(6):583-592. doi: 10.1080/02640410400021278

13. Fenech $M$. The in vitro micronucleus technique. Mutat Res. 2000;455:81-95

14. Fenech M, Chang WP, Kirsch-Volders M, Holland N, Bonassi S, Zeiger E et al. Human MicroNucleus project. HUMN project: detailed description of the scoring criteria for the cytokinesis-block micronucleus assay using isolated human lymphocyte cultures. Mutat Res. 2003;534(1-2):65-75

15. Hartmann A, Pfuhler S, Dennog C, Germadnik D, Pilger A, Speit G. Exercise-induced DNA effects in human leukocytes are not accompanied by increased formation of 8-hydroxy2'-deoxyguanosine or induction of micronuclei. Free Radic Biol Med. 1998;24(2):245-251

16. Umegaki K, Higuchi M, Inove K, Esashi T. Influence of one bout of intensive running on lymphocyte micronucleus frequencies in endurance-trained and untrained men. Int J Sports Med. 1998;19(8):581-585. doi: 10.1055/s-2007971963

17. Knez WL, Jenkins DG, Coombes JS. Oxidative stress in half and full Ironman triathletes. Med Sci Sports Exerc. 2007;39(2):283-288

18. Schneider $C D$, de Oliveira AR. Radicais livres de oxigênio e exercício: mecanismos de formação e adaptação ao treinamento físico. Rev Bras Med Esporte. 2004;10(4):308313. doi: 10.1590/S1517-86922004000400008
19. Reichhold S, Neubauer O, Ehrlich V, Knasmüller S, Wagner KH. No acute and persistent DNA damage after an Ironman triathlon. Cancer Epidemiol Biomarkers Prev. 2008;17(8):1913-1919. doi: 10.1158/1055-9965.EPI-080293

20. Pittaluga $M$, Parisi $P$, Sabatini $S$, Ceci R, Caporossi $D$, Valeria Catani $M$ et al. Cellular and biochemical parameters of exercise-induced oxidative stress: relationship with training levels. Free Radic Res. 2006;40:607-614. doi: $10.1080 / 10715760600623015$

21. Kassie F, Parzefall W, Knasmuller S. Single cell gel electrophoresis assay: a new technique for human biomonitoring studies. Mutat Res/Res Mutat Res. 2000; 463(1):13-31

22. Sahlin K, Shabalina IG, Mattsson CM, Bakkman L, Fernström $M$, Rozhdestvenskaya $Z$ et al. Ultraendurance exercise increases the production of reactive oxygen species in isolated mitochondria from human skeletal muscle. J Appl Physiol. 2010;108(4):780-787. doi: 10.1152/ japplphysiol.00966.2009

23. Franzke B, Halper B, Hofmann M, Oesen S, Peherstorfer $\mathrm{H}$, Krejci $\mathrm{K}$ et al. The influence of age aerobic fitness on chromosomal damage in Austrian institutionalized elderly. Mutagenesis. 2014;29(6):441-445. doi: 10.1093/mutage/ geu042

24. York TP, Brumelle J, Juusola J, Kendler KS, Eaves LJ, Amstadter $A B$ et al. Increased Frequency of Micronuclei in Adults with a History of Childhood Sexual Abuse: A Discordant Monozygotic Twin Study. PLoS ONE. 2013;8(1):1 8. doi: 10.1371/journal.pone.0055337

25. Franzke B, Halper B, Hofmann M, Oesen S, Jandrasits $W, B a i e r l A$ et al. The impact of six months strength training, nutritional supplementation or cognitive training on DNA damage in institutionalized elderly. Mutagenesis. 2015;30(1):147-153. doi: 10.1093/mutage/geu074 